Jarden Rebecca (Orcid ID: 0000-0003-4643-7147)

\title{
Intensive care nurse conceptions of wellbeing: A prototype analysis
}

\section{Authors:}

1) Rebecca Jarden (first \& corresponding author): M.N., R.N.; Department of Nursing, Melbourne School of Health Sciences, 161 Barry St, Carlton, Victoria 3053, Australia \& School of Clinical Sciences, Auckland University of Technology (AUT), North Shore Campus, 90 Akoranga Drive, Northcote, Auckland 0627, New Zealand; phone: 00614 77444548; rebecca.jarden@unimelb.edu.au.

2) Margaret Sandham: (research team member); BHSc (Nursing), DClinPsych., School of Clinical Sciences, Auckland University of Technology (AUT), North Shore Campus, 90 Akoranga Drive, Northcote, Auckland 0627, New Zealand; margaret.sandham@aut.ac.nz.

3) Richard Siegert: (research team member); Ph.D.; School of Clinical Sciences and School of Public Health and Psychosocial Studies, Auckland University of Technology (AUT), North Shore Campus, 90 Akoranga Drive, Northcote, Auckland 0627, New Zealand; richard.siegert@aut.ac.nz.

4) Jane Koziol-McLain: (research team member); Ph.D.; School of Clinical Sciences, Auckland University of Technology (AUT), North Shore Campus, 90 Akoranga Drive, Northcote, Auckland 0627, New Zealand; jane.koziol-mclain@aut.ac.nz.

\section{Abstract}

Background: Accurately conceptualising intensive care nurse work wellbeing is fundamental for successful engagement with workplace wellbeing interventions. Little is currently known about intensive care nurse work wellbeing.

Aims and objectives: Identify intensive care nurses' conceptions of work wellbeing, and measure whether the term 'work wellbeing' is prototypically organised.

Design: Prototype analysis.

Methods: Three linked studies conceptualise intensive care nurse wellbeing. For study one, participants' listed key features of work wellbeing as free text responses. Study two measured whether there was prototypical organisation of these responses. Study three sought to confirm the prototypical organisation of the term 'work wellbeing' through narrative ratings.

Results: Eighty-two New Zealand intensive care nurses were randomly allocated to the three studies, 65 participated. In study one $(n=23)$, most frequently endorsed elements included: workload $(n=14)$, job satisfaction $(n=13)$, and support $(n=13)$. In study two $(n=25)$, highest rated elements included: valued, respect, support, worklife balance, and workplace culture. Elements of support, work-life balance, and workload were in the top five most frequently endorsed elements and also rated in the top 12 most central. Overall, ratings of centrality and number of endorsements were positively correlated $(r=.35, \mathrm{p}<0.05)$. In study three $(n=17)$, nine participants selected the same rating across both narratives with no differentiation on the 11-point scale and were excluded from analysis. The mean score for the central narrative was 7.88 and peripheral narrative was 7.38. Confirmatory analyses did not reach statistical significance.

Conclusions: Unique conceptions of work wellbeing were identified. Workload and work-life balance are central characteristics. Feeling valued, and experiencing respect and support are considered most important.

Relevance to clinical practice: Intensive care nurse conceptions of work wellbeing are fundamental for future measures of work wellbeing, and future interventional studies.

This is the author manuscript accepted for publication and has undergone full peer review but has not been through the copyediting, typesetting, pagination and proofreading process, which may lead to differences between this version and the Version of Record. Please cite this article as doi: $10.1111 /$ nicc.12379 
Key words: work wellbeing, workplace wellbeing, employee wellbeing, ICU, critical care nurse

This article is protected by copyright. All rights reserved. 


\section{Introduction}

Increasingly there are opportunities to draw from psychological capital, and the strengthening evidence base of positive psychological interventions (Hone et al., 2014, Bolier et al., 2013, Sin and Lyubomirsky, 2009, Weiss et al., 2016). The contemporary Intensive Care Unit (ICU) work environment poses stressors throughout a wide range of circumstances. This stress may occur in a variety of ways, such as, psychological stress occurs when the demands of the situation threaten to exceed the resources of the individual (Lazarus and Folkman, 1984). Given such stressors, nurses may be vulnerable to significant harms such as burnout (Epp, 2012, Pereira et al., 2016), compassion fatigue (Jenkins and Warren, 2012), moral distress (Choe et al., 2015) and bullying (Ganz et al., 2015). To engage with workplace wellbeing interventions and programmes, we first require conceptual clarity of work wellbeing in ICU nurses.

\section{Background}

\section{Work wellbeing}

Different occupational groups are thought to have unique features associated with wellbeing (Hamling et al., 2015). For example, for professionals, the five elements of work-life balance, satisfied with education, engaged, meaning and purpose, and autonomy explained the greatest amount of variance in job satisfaction. For labourers, these five elements were work-life balance, absorbed, meaning and purpose, feeling respected, and self-esteem. Thus, ICU nurses may also conceptualise work wellbeing differently to other population groups. For example, in a case study of United Kingdom nurses, wellbeing was related to eight workplace characteristics including the ability to cope with changing demands and re-enforcing feedback loops (Brand et al., 2015). Further, across 97 United States hospitals, both job satisfaction and turnover were significantly influenced by the characteristics of the workplace and the work environment (Baernholdt and Mark, 2009).

Work wellbeing has varied and predominantly Western theoretical views (Grant et al., 2007, Dewe and Kompier, 2008), Page and Vella-Brodrick (2009). Two of the most recent models include Fisher (2014) and Laine and Rinne (2015). Fisher (2014) suggested three major components. Firstly, subjective wellbeing, including job satisfaction and similar positive attitudes, positive affect, and negative affect. Secondly, eudiamonic (i.e., what makes a life worth living; Deci and Ryan, 2008) wellbeing, including engagement, meaning, growth, intrinsic motivation, and calling. Thirdly, social wellbeing, including quality connections, satisfaction with co-workers, highquality exchange relationships with leaders, and social support. Laine and Rinne (2015) proposed a 'discursive' definition with seven key areas relating to: healthy living/working, work/family roles, leadership/management styles, human relations/social factors, work-related factors, working life uncertainties, and personality/individual factors. No one specific feature was evident across all models, however, variations of the element 'relationships' or 'social connections' was apparent in most theoretical models. No models of ICU nurse wellbeing were identified in the literature, representing a significant gap in the present research.

\section{Prototype analysis}

Rosch (1975) proposed that natural language concepts do not always lend themselves to being defined by an 'all or none' phenomenon where all members of the category are assumed to be equally representative. Rather, through series of studies they demonstrated natural language concepts can be categorised by identifying central features ordered by similarity to the prototypical cases, rather than by critical features (Rosch, 1975, Rosch and Mervis, 1975). According to Rosch (1975), when a concept is prototypically organised, some features are more closely associated with the concept than others. Thus, the concept has an internal structure. When asserting a concept is prototypically organised, two criteria need to be met. First, individuals must be able to both identify a 
feature and reliably rate the centrality of the feature to the concept. Secondly, ratings of the centrality of the features to the concept need to influence how individuals think about the concept.

It has been suggested that, for New Zealand workers, wellbeing is prototypically structured (Hone et al., 2015). That is, some elements of wellbeing are more typical than others for some groups. For example, good mental health, good relationships, work-life balance, and good physical health were endorsed as more central to a NZ sample of teachers' and lawyers' conceptions of wellbeing than spirituality, accomplishments, mindfulness, and engagement (Hone et al., 2015). Previous prototype analyses describe a series of studies approach extending from three studies (Hone et al., 2015) to seven studies (Lambert et al., 2009). The key characteristics of five prototype analyses (Weiser et al., 2014, Hone et al., 2015, Kearns and Fincham, 2004, Fehr and Sprecher, 2009, Lambert et al., 2009) are illustrated in Appendix A.

\section{Aims and objectives of study}

Given the limited research investigating ICU nurse work wellbeing, this prototype analysis will investigate how the concept is conceived and defined by ICU nurses. Firstly, the study will identify the elements of ICU nurse work wellbeing. Secondly the relative importance of the elements will be measured. Thirdly, the ability of the ICU nurses to reliably differentiate between elements will be evaluated. The findings will provide a conceptualisation ICU nurse work wellbeing, and how this is like, or different from, common theoretical conceptions of work wellbeing. As such, this study investigated the research questions: How do ICU nurses conceptualise workplace wellbeing? i.e., what are the key elements of workplace wellbeing from their perspective?

\section{Design and methods}

\section{Overview of the three-study prototype analysis}

This prototype analysis involves three connected online studies using different participants, illustrated in Figure 1. Study one asked participants for their conceptions of the features of work wellbeing. These features (items) were coded into elements (a group of common features). Study two used a new sample of participants who rated how central (or important) these elements were to their concept of work wellbeing. In Study three the elements were separated into those that were rated central (most important) and those that were rated peripheral (least important). Drawing from the central and peripheral elements, two narratives were developed, one containing central elements and one containing peripheral elements. A new sample of participants rated how close the narratives were to their conception of work wellbeing.

\section{Participant selection}

Purposeful sampling of the estimated 1,200 registered nurses working in a NZ ICU (Nursing Council of New Zealand, 2015) was conducted through national professional bodies (e.g., New Zealand College of Critical Care Nurses and New Zealand Nurses' Organisation), NZ ICU research nurses, and social media networks (e.g., Facebook ${ }^{\mathrm{TM}}$ groups, Twitter ${ }^{\mathrm{TM}}$, and Linkedl $\mathrm{n}^{\mathrm{TM}}$ ). All NZ RNs presently employed in an ICU were eligible for selection.

\section{Ethical considerations}

This research was conducted in accordance with the Auckland University of Technology Ethics Committee approval (17/180). Advertisements provided potential participants with a URL to the study information webpage. The study information webpage requested participants to indicate their consent by entering their name and e-mail address for the study URL to be emailed to.

\section{Randomisation and allocation}

Participants ( $\mathrm{N}=82$ ) were randomised using random number allocation in Excel $^{\mathrm{TM}}$ and allocated to one of 
the three studies of the Prototype Analysis. Study one $(n=30)$ and two $(n=30)$ were allocated the most participants to seek a rich and diverse set of elements, and to provide strength in the ratings of centrality as these are fundamental to conceptualising work wellbeing and supporting the development of future measures of work wellbeing. Study three was allocated the remaining participants $(n=22)$.

\section{Study one: Generation of prototype elements of 'work wellbeing'}

\section{Procedure}

The 30 participants randomised to study one received an e-mail containing a link to the online questionnaire (see Appendix B; adapted from Fehr, 1988) directing participants to list what they conceive are the key features of 'work wellbeing', as free responses.

\section{Data analysis}

The coding procedure for analysis of these free-responses followed that of Fehr (1988). Firstly, monolexemic linguistic units (i.e., meaningful individual words) were identified and extracted, and responses with modifiers reduced to a single item. Two researchers (RJ \& MS) condensed and categorised items into elements, first independently, then compared and contrasted elements together. This is an approach like that of previous prototype analyses (Hone et al., 2015, Weiser et al., 2014, Kearns and Fincham, 2004). A pre-design, open card sort technique was used (Paul, 2008, Rugg and McGeorge, 1997). A third researcher (JKM) reviewed and resolved any uncertainty in relation to condensing and categorising. Final elements were assessed by one nurse and two lay people using a "think aloud" cognitive interviewing process (see Cohen et al., 2013). Unlike Hone et al.'s (2015) study, no elements were excluded from the final list.

\section{Results}

Of the 30 participants allocated to study one, 23 commenced in the study. The remaining seven did not commence the study after three e-mail reminders. One of the 23 participants partially completed the questionnaire, their partial data were included in the analysis.

\section{Characteristics of participants}

Participants ( $n=23)$ were primarily married $(n=12)$ women $(n=20)$, aged between 25 and 57 years, and identified as NZ European ( $n=15$ ) (followed by NZ Māori, $n=1$; English, $n=3$; South African, $n=1$; American, $n=2$ ), one participant identified as both NZ European and NZ Māori. This was a largely representative sample of the NZ ICU nurse population.

\section{Work wellbeing items and generation of elements}

Thirty-six elements were identified for work wellbeing (see Appendix C). This number of elements was above the threshold of 27 elements sought (based on earlier sample size considerations). Those elements most frequently endorsed by participants included: workload $(n=14)$, job satisfaction $(n=13)$, support $(n=13)$, work life balance $(n=11)$, professional relationships $(n=10)$, professional communication $(n=6)$, caring $(n=6)$, physical health $(n=6)$, and valued $(n=6)$ (see Appendix D).

\section{Discussion}

The frequency of each item recorded by participants varied from 1 to 8 , with no single item being recorded by all participants. The most frequently recorded items were "appropriate workload" followed by "work life balance". Least frequently recorded items included "goals" and "variety". This variation in results from study one suggests there was no one item NZ ICU nurses associated with work wellbeing. However, there were clusters of items that characterised participant responses. For example, there were items that described positive affect, such as 
"happiness" and "fun". There were also positively phrased negative items such as "not overworked" and "not overwhelmed". The prototype for work wellbeing also included behaviours and cognitive activities. Examples of behaviours included "advocate and care" and "provide excellent care". Cognitive activities included "don't feel negatively about going to work". The role of the ICU nurse "caring" for patients was frequently expressed in relation to their work wellbeing. This expression took a variety of forms, but primarily related to self-care enabling patient care. For example, one ICU nurse referred to work wellbeing as "able to meet the requirements of caring for patients with excellence". Another nurse highlighted the need for "a good state of wellbeing...to care for patients...[in]...the intensity of the ICU environment". A further nurse stated work wellbeing was being "able to sustain care for whole shift week". Each of these examples highlights the centrality of work wellbeing to caring.

\section{Study two: Centrality rating of work wellbeing elements}

The second study evaluated whether the term work wellbeing is prototypically organised. To achieve this, study two measured whether participants associate some elements more closely with work wellbeing than others. This determines whether work wellbeing has an internal structure, i.e., certain elements are more strongly associated with work wellbeing than others (Kearns \& Fincham, 2004). To achieve this, individuals must be able to both identify an element and reliably rate the centrality of the element to the concept.

\section{Procedure}

Thirty of the 82 participants were randomly allocated to study two as detailed above in the 'Randomisation and allocation' section. Participants received an e-mail containing a link to the online questionnaire (see Appendix B; adapted from Fehr and Sprecher, 2009, Hone et al., 2015). The questionnaire asked respondents to firstly review a list of possible key elements of work wellbeing (from study one) and, second, rate how central each element is in terms of importance to work wellbeing.

A potential order effect was mitigated firstly through the random assignment of the order of elements for presentation to each participant for rating. Secondly, participants were asked to read all items before commencing their rating. Thirdly, participants were asked to review and amend any ratings prior to moving on to the subsequent question.

\section{Results}

Twenty-five of the 30 participants randomised to study two commenced the study. The remaining five did not commence the study after three e-mail reminders.

\section{Characteristics of participants}

Participants ( $n=25)$ were primarily married $(n=16)$ women $(n=21)$, aged between 25 and 60 years, and identified as NZ European ( $n=17$ ) (followed by English, $n=3$; Chinese, $n=1$; Japanese, $n=1$ ). These participant demographics were consistent with study one participants. Two of the 25 participants provided incomplete demographic data, their partial data were used in the analysis.

\section{Analysis}

Mean centrality ratings were calculated for all responses (see Appendix $D$ ). For work wellbeing, the highest rated elements included valued $(M=9.21, S D=0.93)$, respect $(M=9.17, S D=0.96)$, support $(M=8.92, S D=1.14)$, work-life balance $(M=8.92, S D=1.32)$, and workplace culture $(M=8.92, S D=1.18)$. To measure reliability of the means an intra-class correlation (ICC) was calculated. The ICC was calculated using a split-half model (two-way mixed, absolute agreement $\mathrm{Cl}$ 95\%). This model analysed the 24 participant responses (missing data for 1 participant) with the 36 elements (ICC $=.846, p<.000)$, suggesting good inter-rater reliability. To test for reliability of the rating scale, Cronbach's Alpha was calculated $(\alpha=.87)$. 
Mean centrality ratings were then compared to the number of participant endorsements from study one. Some elements were frequently endorsed by participants and rated central. Comparing the study one and study two data, support (13 endorsements; $M=8.92, S D=1.14$ ), work-life balance (11 endorsements; $M=8.92, S D=1.32$ ), and workload (14 endorsements; $M=8.50, S D=.93$ ) were in the top five most frequently endorsed elements and were also rated in the top 12 most central. However, some elements were endorsed by very few participants yet rated highly in terms of centrality. For example, workplace culture ( 1 endorsement; $M=8.92, S D=1.18$ ) and mental health (1 endorsement; $M=8.83, S D=.87$ ). Overall, ratings of centrality and the number of endorsements were positively correlated $(r=.35, \mathrm{p}<0.05)$. The correlation of centrality rating $(0=$ not at all central $/$ important, $10=$ extremely central / important) and endorsements is illustrated in Appendix E.

\section{Discussion}

The ICU nurses rated some elements as more prototypical of work wellbeing than others. For example, "valued", "respect", and "support" were considered more prototypical than "stress-free", "goals", and "debriefing". The nurses differences between frequency of endorsements and centrality ratings are thought to reflect the measurement of different aspects of the constructs' internal structure, and were commonly found in previous prototype analyses (e.g., see Hone et al., 2015). Given the reliability between the nurses' ratings, this suggests a prototypical organisation to the term work wellbeing. The nurses' ratings of these elements in terms of importance to their conceptions of work wellbeing enabled the development of an illustration depicting these conceptions (see Figure 2). This illustration depicts all elements, with larger size and darker colour demonstrating more central elements.

\section{Study three: The effect of component centrality on conceptions of work wellbeing}

This final study sought to confirm study two's finding of prototypical organisation of the term 'work wellbeing'. To confirm prototypical organisation, ICU nurses' conceptions of work wellbeing would need to be influenced by the centrality of the elements. Study three explored whether participants reliably rated a 'central' narrative higher than a 'peripheral' narrative (e.g., see Hone et al., 2015). We drew from the centrality ratings of the elements in study two to develop the narratives to then test whether ratings of the centrality of the elements influenced how individuals thought about work wellbeing.

\section{Procedure}

The elements rated in study two were split into peripheral and central elements. This was achieved through conducting a median split of the mean centrality ratings (e.g., see Hone et al., 2015). The median for wellbeing was calculated as 8.31. Based on this median, the elements were split into groups: work wellbeing 'central', and work wellbeing 'peripheral' (Appendix F). The 'Central' narratives (Appendix G) used elements with a mean centrality rating of 8.31 or higher. 'Peripheral' narratives (Appendix G) used elements with a mean centrality rating of 8.3 or lower. The average mean for the central work wellbeing elements was 8.66 , and peripheral work wellbeing elements 7.75 .

Drawing from the literature supporting vignette development (e.g., Finch, 1987, Spalding and Phillips, 2007, Miles, 1990), narratives were 1) similar length, 2) similar adjective use (e.g., good, great, well) and 3) used minimal additional words to the elements. Based on the median split, 10 'central' or 'peripheral' elements were used in each respective narrative, like the number used in previous narratives (e.g., Kearns \& Fincham, 2004). Gendered versions of each narrative enabled female participants to receive female central characters in their narrative, and for males, male central characters.

Twenty-two of the 82 participants were randomly allocated to study three. Participants received an e-mail containing a link to the online questionnaire (adapted from Hone et al., 2015). The questionnaire asked respondents firstly to review two hypothetical narratives for work wellbeing developed by the researcher, one containing those elements rated 'central' and the other containing those elements rated 'peripheral', and secondly to rate how close 
each narrative is to their concept of work wellbeing using a 0-10 (eleven-point) rating scale with two end anchors: 'not at all close' and 'extremely close'. Peripheral and central narratives were presented to participants in random order to be rated.

\section{Data analysis}

The means for each narrative were calculated then compared between the central and peripheral hypothetical narratives. Normality of all variables was tested in the sample using visual inspection of each variable's distribution, QQ plots, and the Shapiro-Wilk Test of normality. Comparisons between narrative mean ratings were carried out using independent samples $t$-tests for parametric data and Wilcoxon Signed Rank Test for nonparametric data.

\section{Results}

Of the 22 participants randomised to study three, 20 commenced the study. Of these 20 participants, three discontinued the study prior to responding to the rating questions, and their data was not included in the analysis. The final sample size available for analysis was 17.

\section{Characteristics of participants}

Participants $(n=17)$ were primarily married $(n=12)$ women $(n=16)$, aged between 25 and 63 years, and identified as NZ European ( $n=13$ ) (followed by English, $n=3$; Irish, $n=1$ ). The participant demographics were consistent with study one and two participants.

\section{Analysis}

Normality testing of variables revealed data were non-parametric for the narratives. The mean score for the central narrative was $8.71(S D=1.57)$ and peripheral narrative was $8.47(S D=1.88)$. The median score for both narratives was 9. A Wilcoxon Signed Rank test revealed no statistically significant difference in the ratings of the peripheral and central narratives for work wellbeing, $z=-1.3, p=.19$.

Nine participants selected the same rating across both narratives with no differentiation on the 11-point scale, for example, rated both narratives at 10 . There is a chance that this may have been pattern caused by a response bias similar to that of a leniency error (or generosity error) (e.g., see Cohen et al., 2013). Given this possibility, the data from the remaining 8 participants who had not scored both variables the same were subjected to further analysis (i.e., the 9 'same rating' participants were excluded from the dataset). According to normality testing, the dataset was then parametric. The mean score for the central narrative was 7.88 and peripheral narrative was 7.38. A Paired Samples $t$-test revealed a mean difference in scores for the work wellbeing central and peripheral narratives of .38 with a $95 \%$ confidence interval ranging from -.39 to 1.39. This mean difference was still not significant $(p=.23)$.

\section{Discussion}

Of the 17 ICU nurses in this sample, nine rated no difference between the central and peripheral narratives. This may have been due to the central and peripheral narratives being so similar in their closeness to their conceptions of work wellbeing that they could not differentiate between. In the additional analysis conducted for those participants who rated central and peripheral work wellbeing narratives as different $(n=8)$, the central work wellbeing narrative half a point 'closer' to their conception of work wellbeing than the peripheral work wellbeing narrative (7.88 vs 7.38 ).

Although this was not a statistically significant difference, there were similarities between the results in this study and that of previous prototype analyses. For example, Hone et al. (2015) used a 10-point rating scale and found a mean difference in scores between their central and peripheral wellbeing narratives of 1.29 (7.81 vs 6.52). 
Lambert et al. (2009) used a 15-point rating scale and found a mean difference of 0.65 (13.41 vs 12.76) for gratitude. Fehr and Sprecher (2009) used a 7-point rating scale and found a mean difference of .41 (5.3 vs 4.89) for compassionate love. Given the low participant numbers in the final analysis for this study $(n=8)$, the similarity in our findings to other prototype analyses suggests is a degree of face validity in the mean differences in the central and peripheral narrative ratings.

The small sample sizes meant cohort effects in conceptualisations of work wellbeing were not examined for possible demographic differences in responses, for example, age, gender, ethnicity, and nursing experience. Given there was no significant difference between the means for work wellbeing, we cannot confirm in this sample of ICU nurses work wellbeing is prototypically arranged.

\section{General discussion}

This prototype analysis of work wellbeing sought to conceptualise the term for a sample of NZ ICU nurses. Studies one and two demonstrated that ICU nurses' conceptions of work wellbeing are structured prototypically, however the small sample size of study three failed to reach statistical significance. The concept of 'relationships' was strongly evident in a variety of elements, such as, personal relationships, professional relationships, teamwork, support, and professional communications. Peterson (2006) suggests "other people matter" (p. 249), this statement appears true in this study. For workers in organisations, the dimensions of effective work relationships are dynamic and integrative (Ferris et al., 2009). The importance of relationships in the workplace was reflected in all identified work wellbeing models and apparent in this study too.

Of the theoretical perspectives and models of wellbeing (Seligman, 2011, Durie, 1985, Ryff, 1989, Palmer, 2004) and work wellbeing (Grant et al., 2007, Dewe and Kompier, 2008, Page and Vella-Brodrick, 2009, Fisher, 2014, Laine and Rinne, 2015), no one model sufficiently depicted this study's sample of ICU nurses' conceptions of work wellbeing. The work wellbeing model of Dewe and Kompier (2008) most comprehensively captured the ICU nurse conceptions of work wellbeing. That is, many of the elements in the conceptual overview of factors that affect wellbeing at work by Dewe and Kompier (2008) were reflected in the elements identified by ICU nurses. Notably, this model was also the most detailed model identified, so was also the most likely to contain these elements.

Rather than there being a definition of work wellbeing with specific elements that meet the 'all-or-none' criteria, this research suggests work wellbeing may be better described as a collection of elements; a rich and multifaceted construct. For the term work wellbeing, we found support for the assertion of Rosch (1975) that natural language concepts can be categorised by identifying central features ordered by similarity to the prototypical cases, rather than by critical features (Rosch, 1975, Rosch and Mervis, 1975).

This research found, for some ICU nurses', the term work wellbeing was prototypically organised, but study three's confirmatory analysis was not statistically significant due to the small sample size. This differs from previous prototype analyses as they identified statistically significant evidence for prototypical organisation. Of note, all previous prototype analyses identified in the literature confirmed some degree of prototypical organisation, which may point to a publication bias. Notably, the results of just the eight nurses who differentiated between the central and peripheral narratives was comparable to the findings of (Hone et al., 2015) who found a mean difference in scores for wellbeing central and peripheral scenarios of 1.29 ( $95 \% \mathrm{Cl}$ from .198 to 2.37).

\section{Limitations}

For this research, there is a likely sampling bias caused by low sample size. Previous prototype analyses show no evidence of calculating nor justifying sample sizes, likely due to the inductive approach of the prototype analysis. Personal communication with two first authors of previous prototype analyses (Weiser et al., 2014, Hone et al., 2015) highlighted the focus more towards the number of features and elements generated rather than sample size, particularly for study one. Using this focus, statistically significant results were not obtained in the third study. This suggests that considering the number of elements to confirm the sample size may be insufficient.

The closeness of the ratings of the central and peripheral narratives in study two may have been due to the 
items from study one being allocated through the research process to too broad elements which resulted in participants rating them similarly in study two. The researchers have provided both the 'items' and 'elements' for readers' own judgements of allocation processes (see Appendix A). In sum, although we have sought to avoid Type One errors, it's likely we have introduced Type Two errors.

\section{Recommendations for future prototype analyses}

Firstly, providing participants of study two with all items identified in study one, may be an option for small and unique samples in future research. Secondly, drawing participants attention to the specific differences within the narratives (e.g., by highlighting the different elements), asking participants to rank the two narratives, or asking participants to choose one narrative over the other all may impact on the participants differentiation between narratives - although each would potentially introduce Type One errors. Thirdly, adding a fourth study to test participant memory/recall of elements associated with work wellbeing may have increased participants differentiation between central and peripheral elements.

\section{Implications for practice}

Future-proofing the ICU nursing workforce requires a multi-faceted approach. One essential component is the conceptions of key stakeholders, nurses. Workload and work-life balance were identified by ICU nurses as central characteristics to their work wellbeing. Feeling valued, and experiencing respect and support are considered most important. These ICU nurse conceptions of work wellbeing provides the foundations for rigorous measures and workplace wellbeing programmes to be crafted. This brings us one step closer in optimising the wellbeing ICU nurses.

\section{Conclusions}

This study conceptualised ICU nurse work wellbeing for a sample of NZ ICU nurses. Appropriate workload and work-life balance were key characteristics to work wellbeing, and being valued, respect, and support were most important. These unique conceptions of ICU nurses will be fundamental in future measures of work wellbeing, and future interventional studies.

\section{Impacts}

What is known about the subject:

- The contemporary ICU work environment poses stressors throughout a wide range of circumstances.

- Accurately conceptualising intensive care nurse work wellbeing is fundamental for the successful development of valid and reliable measures to evaluate the impact of wellbeing interventions.

- Prototype analysis has been used to investigate natural language concepts with a "fuzzy collection of features".

\section{What this paper contributes:}

- No single element was identified as a characteristic of work wellbeing by all ICU nurses.

- "Appropriate workload" and "work-life balance" were the two most frequently reported characteristics of work wellbeing.

- "valued", "respect", and "support" were considered most important to the nurses' concept of work wellbeing.

- Rather than there being a definition of work wellbeing with specific elements that meet the 'all-or-none' criteria, this research suggests work wellbeing may be better described as a collection of elements; a rich and multifaceted concept. 
Acknowledgements: Thank you to the NZ ICU RNs who participated in the study. Thank you to the professional organisations (e.g., NZNO \& NZNO's NZCCCN) that supported study advertising.

Conflict of interest statement: The authors have no conflicts of interest to declare

Funding and financial disclosure: This research has not received funding.

This article is protected by copyright. All rights reserved. 


\section{References}

Baernholdt M \& Mark B (2009). The nurse work environment, job satisfaction and turnover rates in rural and urban nursing units. Journal of Nursing Management; 17: 994-1001.

Bolier L, Haverman M, Westerhof GJ, Riper H, Smit F \& Bohlmeijer E (2013). Positive psychology interventions: A meta-analysis of randomized controlled studies. BMC Public Health; 13: 1-20.

Brand S, Fleming L \& Wyatt K (2015). Tailoring healthy workplace interventions to local healthcare settings: A complexity theory-informed workplace of well-being framework. The Scientific World Journal; 2015: 340820.

Choe K, Kang Y \& Park Y (2015). Moral distress in critical care nurses: A phenomenological study. Journal of Advanced Nursing; 71: 1684-1693.

Cohen R, Swerdlik M \& Sturman E (2013). Psychological testing and assessment: An introduction to tests and measurement. New York, NY: McGraw-Hill.

Deci E \& Ryan R (2008). Hedonia, eudaimonia, and well-being: An introduction. Journal of Happiness Studies; 9: 1-11.

Dewe P \& Kompier M (2008). Foresight mental capital and wellbeing project. Wellbeing at Work: Future Challenges. London, UK: The Government Office for Science.

Durie M (1985). A Māori perspective of health. Social Science \& Medicine; 20: 483-486.

Epp K (2012). Burnout in critical care nurses: A literature review. Dynamics : The Official Journal of the Canadian Association of Nurses; 23: 25-31.

Fehr B (1988). Prototype analysis of the concepts of love and commitment. Journal of Personality and Social Psychology; 55: 557-579.

Fehr B \& Sprecher S (2009). Prototype analysis of the concept of compassionate love. Personal Relationships; 16: 343-364.

Ferris G, Liden R, Munyon T, Summers J, Basik K \& Buckley M (2009). Relationships at work: Toward a multidimensional conceptualization of dyadic work relationships. Journal of Management; 35: 1379-1403.

Finch J (1987). The vignette technique in survey research. Sociology; 21: 105-114.

Fisher C (2014). Conceptualizing and measuring wellbeing at work. In: Cooper CL (ed.) Wellbeing: A complete reference guide. Hoboken, NJ: Wiley.

Ganz F, Levy H, Khalaila R, Arad D, Bennaroch K, Kolpak O, Drori Y, Benbinishty J \& Raanan O (2015). Bullying and its prevention among intensive care nurses. Journal of Nursing Scholarship; 47: 505-511.

Grant A, Christianson M \& Price R (2007). Happiness, health, or relationships? Managerial practices and employee well-being tradeoffs. Academy of Management Perspectives; 21: 51-63.

Hamling K, Jarden A \& Schofield G (2015). Recipes for occupational wellbeing: An investigation of the associations with wellbeing in New Zealand workers. New Zealand Journal of Human Resource Management; 15: 151173.

Hone L, Jarden A \& Schofield G (2014). An evaluation of positive psychology intervention effectiveness trials using the RE-AIM framework: A practice-friendly review. The Journal of Positive Psychology; 10: 303-322.

Hone L, Schofield G \& Jarden A (2015). Conceptualizations of wellbeing: Insights from a prototype analysis on New Zealand workers. New Zealand Journal of Human Resource Management; 15: 97-118.

Jenkins B \& Warren N (2012). Concept analysis: Compassion fatigue and effects upon critical care nurses. Critical Care Nursing Quarterly; 35: 388-395.

Kearns J \& Fincham F (2004). A prototype analysis of forgiveness. Personality and Social Psychology Bulletin; 30: 838855.

Laine P \& Rinne R (2015). Developing wellbeing at work: Emerging dilemmas. International Journal of Wellbeing; 5.

Lambert N, Graham S \& Fincham F (2009). A prototype analysis of gratitude: Varieties of gratitude experiences. Personality and Social Psychology Bulletin; 35: 1193-1207. 
Lazarus R \& Folkman S (1984). Stress, Appraisal and Coping. New York: Springer.

Miles MS (1990). New methods for qualitative data collection and analysis: vignettes and pre-structured cases. International Journal of Qualitative Studies in Education; 3: 37-51.

Nursing Council of New Zealand (2015). The New Zealand nursing workforce: A profile of nurse practitioners, registered nurses and enrolled nurses. Wellington, NZ: NCNZ.

Page K \& Vella-Brodrick D (2009). The "what," "why" and "how" of employee wellbeing: A new model. Social Indicators Research; 90: 441-458.

Palmer S (2004). Homai te Waiora ki Ahau: A tool for the measurement of wellbeing among Maori-the evidence of construct validity. New Zealand Journal of Psychology; 33: 50-58.

Paul C (2008). A modified delphi approach to a new card sorting methodology. Journal of Usability Studies; 4: 7-30.

Pereira S, Teixeira C, Carvalho A \& Hernández-Marrero P (2016). Compared to palliative care, working in intensive care more than doubles the chances of burnout: Results from a nationwide comparative study. PLoS One; 11.

Peterson C (2006). A primer in positive psychology. New York: Oxford University Press.

Rosch E (1975). Cognitive representations of semantic categories. Journal of experimental psychology. General; 104: 192-233.

Rosch E \& Mervis C (1975). Family resemblances: Studies in the internal structure of categories. Cognitive Psychology; 7: 573-605.

Rugg G \& McGeorge P (1997). The sorting techniques: a tutorial paper on card sorts, picture sorts and item sorts. Expert Systems; 14: 80-93.

Ryff C (1989). Happiness is everything, or is it? Explorations on the meaning of psychological well-being. Journal of Personality \& Social Psychology; 57: 1069-1081.

Seligman M (2011). Flourish: A visionary new understanding of happiness and well-being. Sydney, Australia: William Heinemann.

Sin NL \& Lyubomirsky S (2009). Enhancing well-being and alleviating depressive symptoms with positive psychology interventions: A practice-friendly meta-analysis. Journal of Clinical Psychology; 65: 467-487.

Spalding N \& Phillips T (2007). Exploring the use of vignettes: From validity to trustworthiness. Qualitative Health Research; 17: 954-962.

Weiser D, Lalasz C, Weigel D \& Evans W (2014). A prototype analysis of infidelity. Personal Relationships; 21: 655675.

Weiss L, Westerhof G \& Bohlmeijer E (2016). Can we increase psychological well-being? The effects of interventions on psychological well-being: A meta-analysis of randomized controlled trials. PLOS ONE; 11: e0158092. 


\section{Study one:}

Item generation

What are the features

of work wellbeing?

(exploratory)
Study two:

Element rating

Are some elements

more strongly

associated with work

wellbeing?

(measures prototypical

organisation)
Study three:

Narrative rating

Does element centrality

influence participants

conceptions?

(confirms prototypical organisation)

Figure 1. Three-study prototype analysis.

This article is protected by copyright. All rights reserved. 


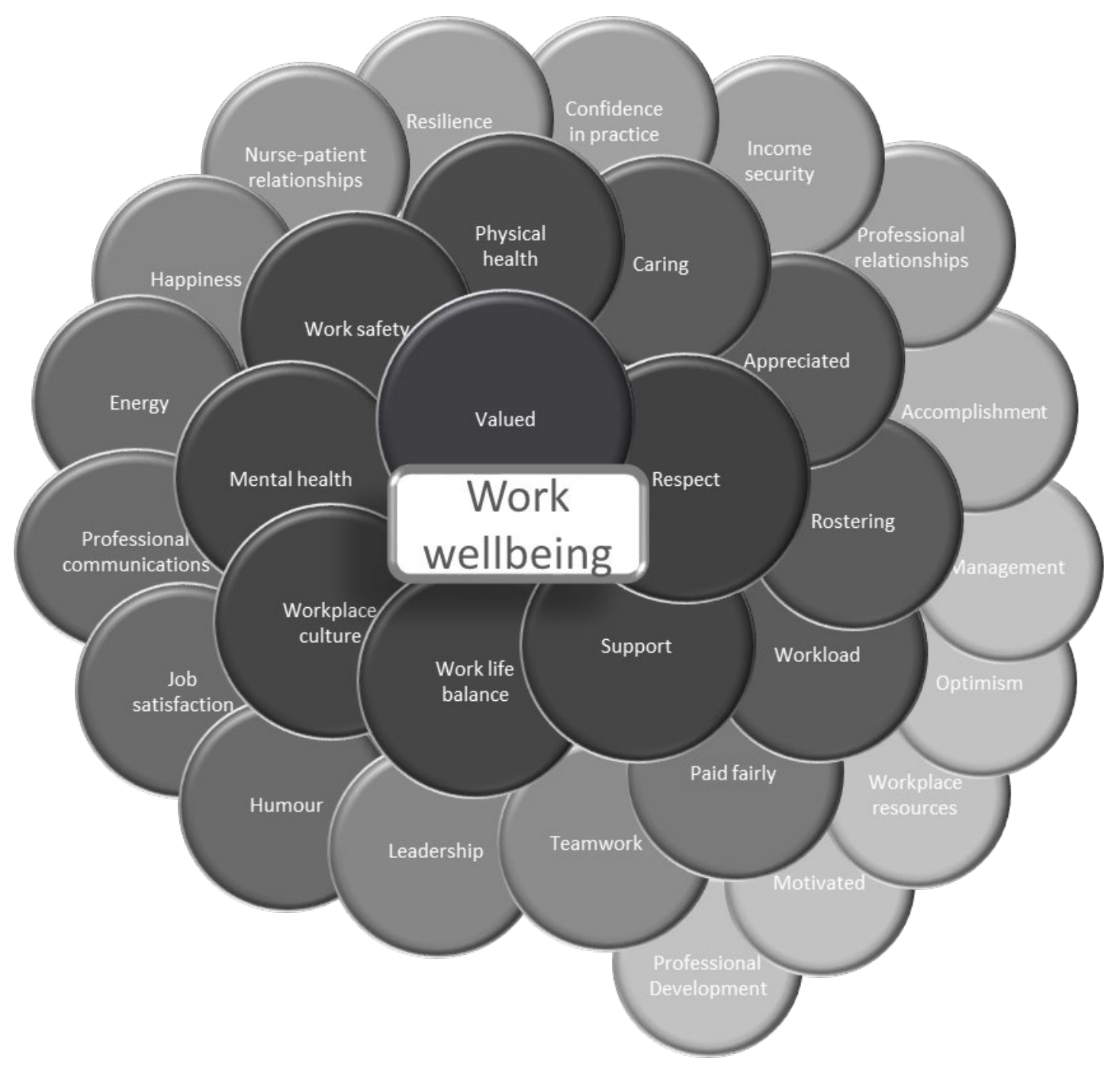

Figure 2. Illustration depicting ICU nurse conceptions of work wellbeing, larger size and darker shading represents more central elements. 


\section{University Library}

\section{- M M N E R VA A gateway to Melbourne's research publications}

Minerva Access is the Institutional Repository of The University of Melbourne

Author/s:

Jarden, RJ;Sandham, M;Siegert, RJ;Koziol-McLain, J

Title:

Intensive care nurse conceptions of well-being: a prototype analysis

Date:

2018-11-01

Citation:

Jarden, R. J., Sandham, M., Siegert, R. J. \& Koziol-McLain, J. (2018). Intensive care nurse conceptions of well-being: a prototype analysis. NURSING IN CRITICAL CARE, 23 (6), pp.324-331. https://doi.org/10.1111/nicc. 12379.

Persistent Link:

http://hdl.handle.net/11343/284375 